\title{
On the starting blocks
}

\author{
Ilaria Ciofini · Carlo Adamo
}

Published online: 4 September 2014

(C) Springer-Verlag Berlin Heidelberg 2014

A new and exciting adventure will start for us in January 2015, that of serving as Editors-in-Chief for Theoretical Chemistry Accounts (TCA), a journal with a glorious history that has tracked the development of theoretical chemistry. Succeeding such prestigious Editors-in-Chief as Hermann Hartmann, Klaus Ruedenberg, Don Truhlar and Chris Cramer is an honour and a duty to which we will commit our best, counting on our complementary scientific attitudes and expertise.

Especially thanks to the active and inventive leadership of Dr. Cramer, we inherit the editorship of a journal that is vital and proficient in fast publication of high-standard papers covering a wide variety of topics in theoretical chemistry. In line with Dr. Cramer's editorship, we will continue to target excellence in science and efficiency in publication which are nowadays renowned as strong points of TCA.

One of the main goals of our editorship will be to follow the rapid growth, witnessed especially in the last years, of emerging domains encompassed by theoretical chemistry including now biology, materials science and physics. In this context, the development and the application of theoretical methods are necessarily entangled and a reference journal in this field, such as TCA, should in our opinion cover both aspects with the same intensity. We wish to follow the evolution of theoretical chemistry attracting, besides contributions from traditional theoretical chemists, also those from authors of communities straddling the borders of traditional disciplines. Particular care will be devoted to editorial initiatives that promote the achievements of young and emerging scientists.

Of the many challenges we faced in science, accepting this joint editorial responsibility is clearly one of the most gratifying and permits us to assert that science, besides individuals, also rests on collaboration and constructive sharing. Indeed, conscious that a journal is made not only by its editorial board and staff, but also by its readers, authors and referees, we count on the active collaboration and initiative of all these partners, which we hope constantly to stimulate, being ready to support their proposals for new initiatives and activities.

Please join us in continuing this bountiful adventure in theoretical chemistry called TCA.

I. Ciofini $(\bowtie) \cdot$ C. Adamo $(\bowtie)$

Equipe Chimie Théorique et Modélisation, IRCP UMR CNRS

8247, ENSCP-Chimie ParisTech, 11, rue Pierre et Marie Curie,

75005 Paris, France

e-mail: ilaria.ciofini@ chimie-paristech.fr

C. Adamo

e-mail: carlo.adamo@chimie-paristech.fr 